\title{
Performance analysis of an on-site hydrogen facility for fuel cell trains
}

\author{
Francesco Piraino, Matteo Genovese and Petronilla Fragiacomo \\ Department of Mechanical, Energy and Management Engineering, University of Calabria, 87036 \\ Arcavacata di Rende, Cosenza, Italy
}

\begin{abstract}
Fuel cell technologies and hydrogen can represent a potential and powerful enabler for replacing traditional diesel vehicles, especially in railways. In this train of thought, the present paper aims to investigate a fuel cell hybrid powertrain for a regional route. The main powertrain components are numerically modeled and the railway operations are simulated. The results achieved, in terms of power demand, efficiency and hydrogen consumption, are discussed and they are useful for properly sizing the refueling system. As a matter of fact, the train will be fueled with compressed hydrogen, produced on-site at a hydrogen central depot, where a hydrogen refueling station is thought to be installed. The hydrogen generation unit is considered to be a PEM unit, operating at $353 \mathrm{~K}$ and 20 bar. The produced hydrogen is then compressed by mean of a volumetric compressor and then stored in hydrogen tank type II, at 350 bar. The dispensing scheduling is based on the daily hydrogen demand required by the fuel cell-based train route, according to the railway timetable.

The system is indeed investigated from a technical point of view, proving the integration of such systems to represent a clean, sustainable, and flexible option.
\end{abstract}

\section{Introduction}

The current worldwide emission scenario shows an important contribution belonging to transport sector. In 2018, $8 \mathrm{Gt}$ of carbon dioxide emissions have been produced from technologies adopted in the mobility sector [1], being responsible for the $26 \%$ of the overall picture. Emissions are forecasted to increase even more, and the current technologies are still responsible for high pollution.

Rail is considered among the most efficient transport modes, in terms of energy use and emissions, and a marked shift of freight and passenger transport is expected towards rail applications. Further actions are needed, to guarantee a clean and efficient operation. Among the several options, hydrogen is widely recognized as an energy vector and as an alternative fuel [2], and hydrogen-based solutions are advancing with a marked pace [3]. Fuel cell (FC) technology presents several benefits: a more efficient, noiseless and performant operation from an energy point of view, shared with the stack scalability, indirect electrification, and flexible supply [4,5].

Several authors have investigated the adoption of fuel cells in rail applications, designing numerical models, prototypes and full-size vehicles. Among them, Longo et al. [6] performed a preliminary sizing analysis of a fuel cell hybrid railway; for a real $408-\mathrm{km}$ route, approximately $51 \mathrm{~kg}$ are consumed and a tank system with $1224 \mathrm{~L}$ volume and $1090 \mathrm{~kg}$ weight is necessary. Hoffrichter et al., in [7], developed a narrow FC prototype locomotive, achieving about $10 \%$ and $40 \%$ for vehicle and FC system efficiency. Zang et 
al., in [8], experimentally tested a fuel cell/battery/supercapacitor train, consuming almost $1.5 \mathrm{~kg}$ of hydrogen for 1-hour drive cycle.

Heavy-duty applications require severe conditions on the refueling side, and the hydrogen economy needs to overcome several barriers to guarantee the complete rolling out of hydrogen technologies. High-pressure storage is needed to guarantee an extended mileage, with a consequence of heavy tanks and complex refueling infrastructures [9]. The chicken-and-egg problem is still present, and more hydrogen stations need to be installed, both with private efforts and government supports [10].

Based on 2018 data, the specific energy demand for compression for the low pressure compressor (up to $350 \mathrm{bar}$ ) resulted to be around $1.6 \mathrm{kWh} / \mathrm{kg}[11,12]$. The compression (up to 700 bar) and dispenser stages have also a significant energy consumption, accounting for $2.25 \mathrm{kWh} / \mathrm{kg}$ [13], while the cooling block adds a system load of $1.40 \mathrm{kWh} / \mathrm{kg}$ [14].

Expensive and complex components are needed, such as booster compressors, highpressure storage and complex cooling configurations, requiring a strict monitoring on the station [15]. For these conditions, the hydrogen supply plays a crucial role, as marked by Kolbe [16]: if the energy adopted for the hydrogen production does not come from green sources, the environmental impact is still high and investments on hydrogen heavy-duty mobility might be not worthy. Water electrolysis could enable a clean hydrogen production, supporting also the supply chain with an on-site operation, avoiding extracosts of external supply [17].

In this train of thought, it is visible how heavy-duty applications require a more intensive research effort: for a worldwide spreading out, even all the benefits discussed above, fuel cell-based hybrid systems have to face a limited market penetration, due to the lack of hydrogen refueling stations and high costs of the fuel cell system

As a novelty, the present paper presents a technical assessment of a fuel cell hybrid powertrain for a regional route. The train is considered to be fueled with compressed hydrogen, produced on-site at a hydrogen central depot, where a hydrogen refueling station is thought to be installed. The hydrogen generation unit is considered to be an electrolysis unit, operating at $353 \mathrm{~K}$ and 20 bar. The produced hydrogen is then compressed by mean of a volumetric compressor and then stored in hydrogen tank type II, at 350 bar. The dispensing scheduling is based on the daily hydrogen demand required by the fuel cellbased train route, according to the railway timetable.

The main powertrain and hydrogen station components are numerically modeled and the railway operations are simulated. The results achieved, in terms of power demand, efficiency and hydrogen consumption, are discussed and they are useful for properly sizing the refueling system. The system is indeed investigated from a technical point of view, proving the integration of such systems to represent a clean, sustainable, and flexible option.

\section{Model Description}

The implemented mathematical model deals with the analysis of the hybrid powertrain and its related parameters, such as the drive cycle, the track morphology, and the overall vehicle mass. The first powertrain investigation is focused on the components' choice and 
layout, since a full-powered fuel cell vehicle cannot satisfy the rapid transients and quick power variations.

For this reason, a hybrid system is taken into account, mainly composed of a fuel cell (FC) system and other energy storage technologies, namely battery and/or supercapacitor, according to the drive cycle and morphology parameters [18].

The fuel cell system and the energy storage system (ESS) are load-connected by means of DC/DC converters, modeled by considering their operation with an energy efficiency. When the vehicle occurs to perform in deceleration, the produced energy is recovered through a regenerative brake strategy.

The powertrain model can be divided into three main sub-areas: the power demand calculation block (PDC), the energy management system (EMS), and the energy sources. A model scheme is shown in Fig.1: the main inputs are the track morphology, train characteristics and drive cycle. The model is able to calculate the vehicle needs in terms of power demand, providing the best configuration and selecting the sources needed. Once the system is sized, the powertrain is dynamically simulated, analyzing the behavior of the power sources which are controlled by the EMS. The powertrain performance are calculated and the hydrogen consumption tracked. The powertrain model results will be then used as main inputs of the hydrogen station model.

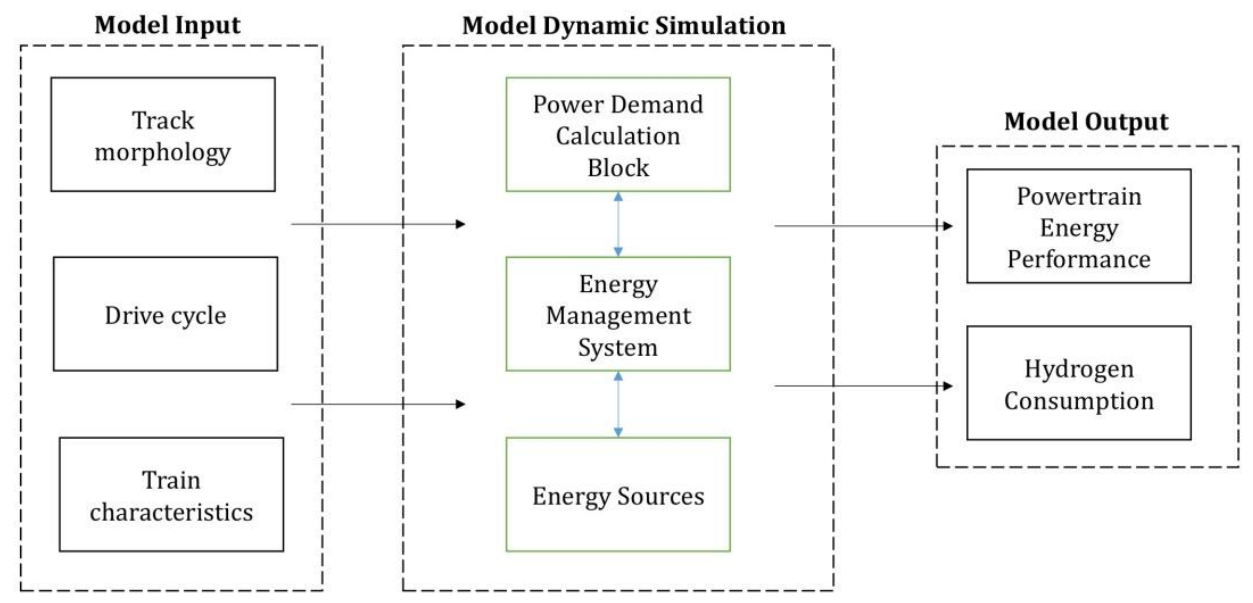

Fig. 1. Powertrain model description.

The authors have already developed and implemented the numerical models [19], and in the following sections, each subsystem will be briefly described.

The total power demand is obtained through the power demand calculation block that is based on the Lomonossoff's equations, explained in eq. 1 .

The vehicle features, such as mass (M), length and frontal area, are taken into account in the vehicle resistance losses (Res). The power required is calculated starting from the tractive force $\left(\mathrm{F}_{\mathrm{tr}}\right)$, solving the eq. 2 , where a is the acceleration, $\alpha$ is the altitude slope angle, $\lambda$ is the dynamic mass coefficient and $g$ is the gravitational acceleration.

$$
M(1+\lambda) a=F_{t r}-R e s-M g \sin (\alpha)
$$


Once the vehicle demand is calculated, in each step of time, the power sharing, among the energy sources, is achieved, by means of an Equivalent consumption minimization strategy. In this way, the control system calculates the FC power demand ( $\mathrm{P}_{\mathrm{FCopt}}$ ), minimizing the objective function, reported in eq. 2. It is depending on the hydrogen consumption $\left(\mathrm{C}_{\mathrm{FC}}\right)$ and the equivalent hydrogen consumption of the ESS ( $\left.\mathrm{C}_{\mathrm{H} 2 \mathrm{ESS}}\right)$, multiplied by a corrective factor, function of the ESS state of charge ( $\mathrm{k}_{\mathrm{ESS}}$ ) [20]. The remaining power is provided by the energy storage system.

$$
P_{F C o p t}=\operatorname{argmin}\left(C_{F C}+k_{E S S} C_{H_{2} E S S}\right)
$$

At this time, the power rate selected is imposed to the energy sources. The main model is the FC hybrid powertrain. The fuel cell model is based on a voltage balance, subtracting the voltage losses, such as activation $\left(\mathrm{V}_{\text {act }}\right)$, ohmic $\left(\mathrm{V}_{\mathrm{ohm}}\right)$ and concentration losses $\left(\mathrm{V}_{\text {conc }}\right)$ from the Nernst voltage $\left(\mathrm{E}_{\mathrm{N}}\right)$. Consequently, the fuel cell power $\left(\mathrm{P}_{\mathrm{FC}}\right)$ is calculated by the product between the fuel cell current $\left(\mathrm{I}_{\mathrm{FC}}\right)$ and voltage, as explain in eq. 3 . The battery system and the DC/DC system converters have been modeled by adopting simplified models.

$$
P_{F C}=\mathrm{I}_{\mathrm{FC}}\left(E_{N}-V_{a c t}-V_{o h m}-V_{c o n c}\right)
$$

Once the powertrain of the innovative train is simulated and the hydrogen consumption is calculated, the results are used as inputs of a parallel implemented model, dealing with the hydrogen production and dispensing facility. Fig. 2 shows a brief scheme of the model operation. The main inputs are related to the daily hydrogen request, according to the hybrid fuel cell train route and its performance. Target pressure and operating temperature are also needed, since they strongly affect the electrolyzer operation. The model thus simulates the system operation by starting from the electrochemical block, involving the stack voltage as a function of Nernst Potential, the ohmic over-voltages, the activation overvoltages and the diffusion over-voltages. Partial pressures, calculated with the equation of state, are also needed in the anodic and cathodic chambers. Thermal phenomena are included by considering a temperature trend via a lumped approach. Most of the parameters are as a function of the operating current, whose value depends on the hydrogen daily production.

The facility produces hydrogen via Polymer Electrolyte Membrane (PEM) electrolysis, that is modeled through a zero-dimensional and multi-physics model, previously developed [21]. The hydrogen generation process is strongly related to the operating current, as shown in eq. 4 . The operating current and the number of electrolytic cells $N_{c}$ are calculated with an iterative process, involving the daily hydrogen request and the evaluation of the Faraday Efficiency, $\eta_{\text {Faraday }}$, by guaranteeing the current to lay within a range of optimal performance, in terms of energy efficiency, previously investigated, between $100 \mathrm{~A}$ and $135 \mathrm{~A}$.

$$
N_{c} \cdot I=\dot{m}_{H 2} \cdot \frac{z \cdot F}{\eta_{\text {Faraday }} \cdot M W}
$$

From experimental data, Faraday Efficiency has been modeled with a polynomial interpolation as function of stack current I [21]. 


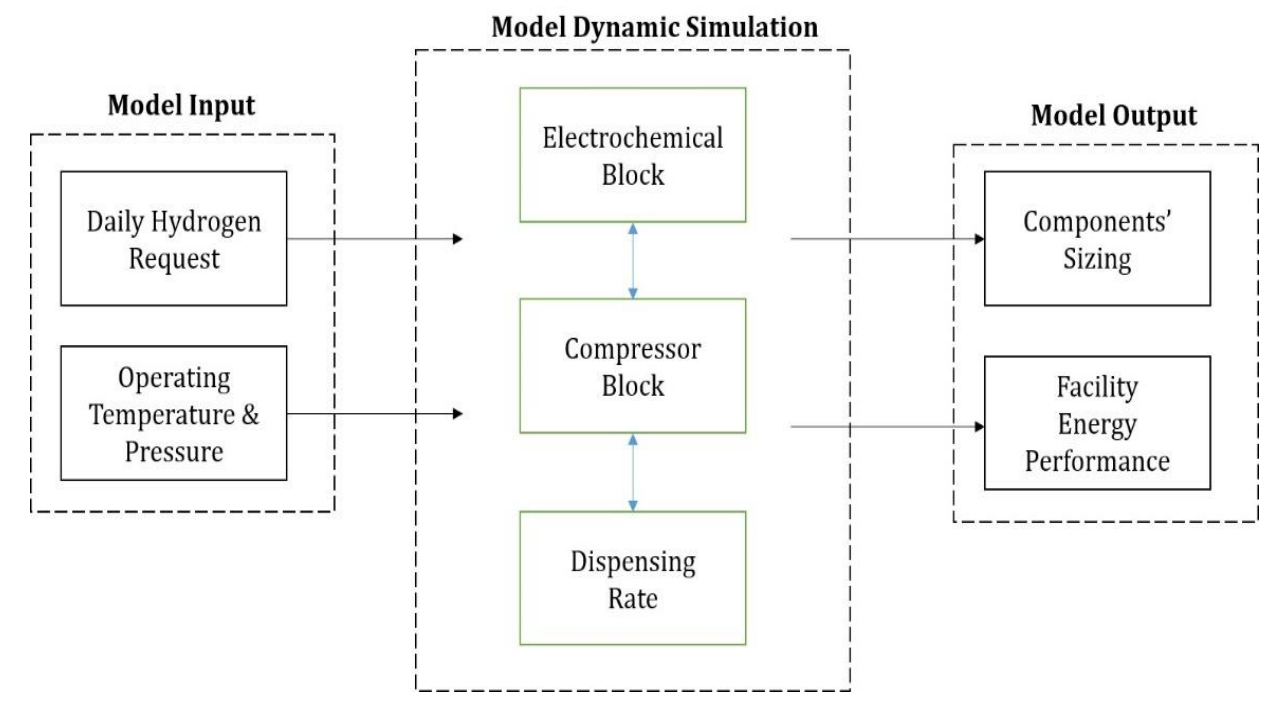

Fig. 2. Hydrogen infrastructure model description.

The stack power is derived by calculating the stack voltage and multiplying it for the current and the number of cells. Ancillary power is also included, thanks to a previously developed fitting curve validated with experimental data [21]. A hydrogen station layout normally includes the presence of the first stage of compression, storage, and dispenser [22]. The model thus includes the energy evaluation of the compression process, and of the dispensing procedure. The compressor is considered to be modeled with a polytropic process and intermediate intercooling stages, and its operation has been already described in the authors' previous paper [23]. For the gaseous storage, three horizontal steel vessels (Type II) have been chosen, with a nominal pressure of $35 \mathrm{MPa}$.

The dispensing rate in literature is accounted as a comprehensive value with the compressor, up to $2.25 \mathrm{kWh} / \mathrm{kg}$. For the purpose of this paper, since compression rate has been already modeled, the dispensing rate is considered as the difference between the overall literature value and the modeled compression rate, with a final energy consumption for dispensing of $0.28 \mathrm{kWh} / \mathrm{kg}$ of hydrogen.

\section{Case Study}

The simulated case study is related to a Southern Italy track: a regional rail track is analysed, that links Reggio Calabria and Paola (Fig. 3). It is the most important and used rail track in Calabria, useful for transporting passengers and goods from Calabria to Northern Italy. In this case study, passenger trains are simulated and four stops are considered, in the main rail stations (Paola, Lamezia, Rosarno and Reggio Calabria). Fig. 4 shows the track morphology and the drive cycle speed of the Paola-Reggio Calabria lines. The altitude variations is in a small interval, between the sea level and $220 \mathrm{~m}$ a.s.l, considering the track length, approximately $360 \mathrm{~km}$ for a round trip, since this line is mainly located along the coastline.

Regarding the drive cycle (Fig. 4), a simplified trend is used, constituted by three different sections: constant acceleration, constant speed and constant deceleration. A 
standard passenger train is considered, therefore high-speed levels are not reached: the maximum speed achieved is $110 \mathrm{~km} / \mathrm{h}$. Due to the rail line length and standard speed vehicle, almost 10 hours are needed for a round trip, thus, two complete cycles per day are considered.

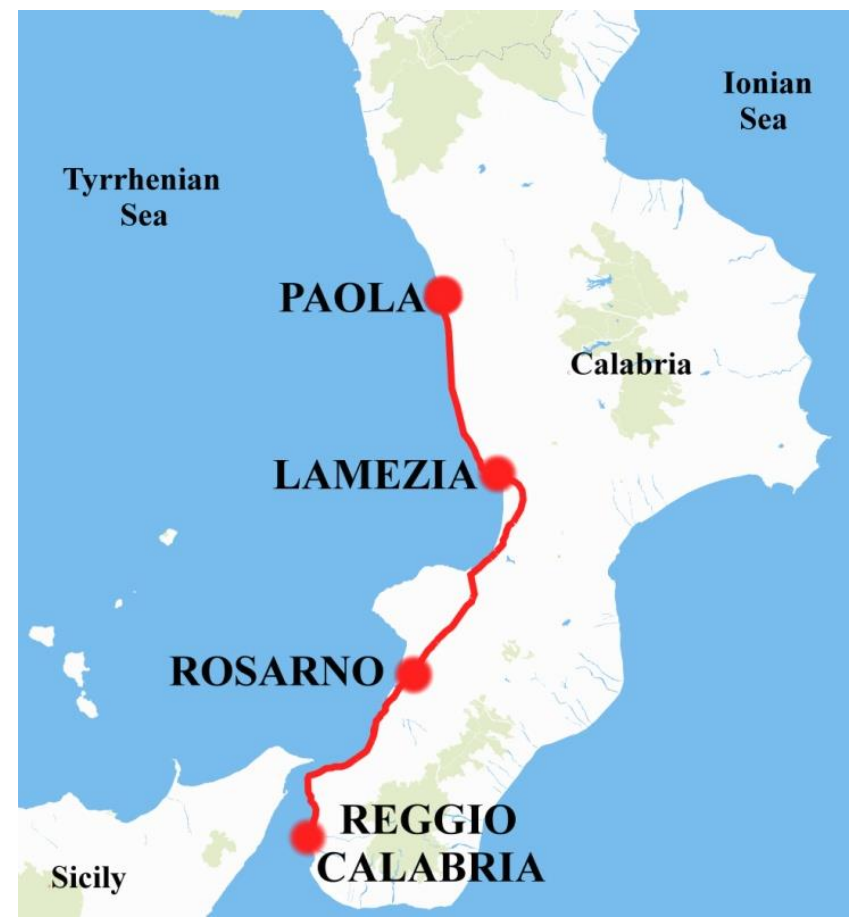

Fig. 3. Journey track and intermediate stops.

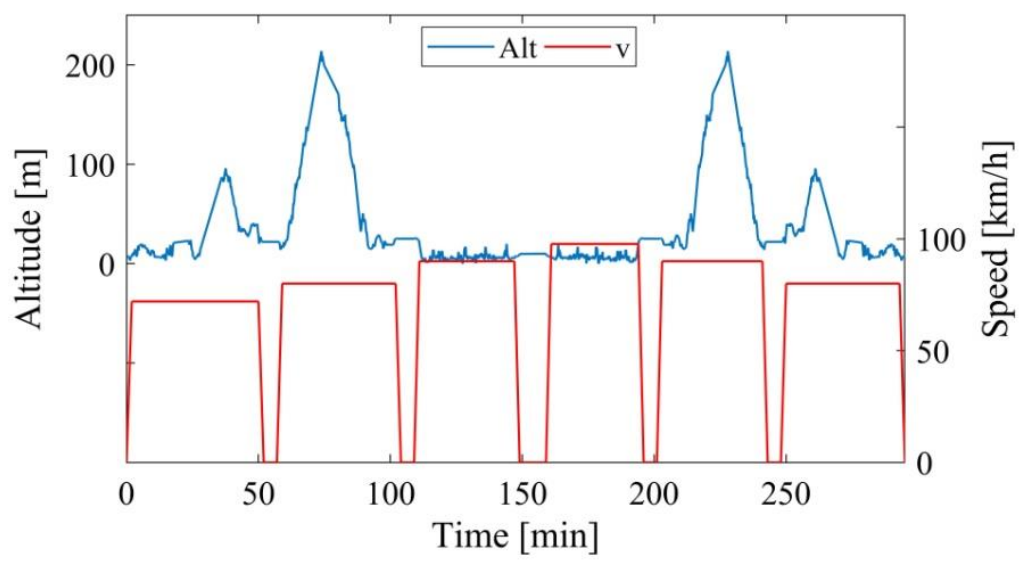

Fig. 4. Track morphology and vehicle drive speed. 
According to the energy and power vehicle demand, a hybrid powertrain is simulated; particular focus is oriented on the fuel cell stack, the core of the propulsion system. Two parallel $180 \mathrm{~kW}$ fuel cells are considered; its main specs are listed in Table 1. Regarding the energy storage, a battery pack is used to provide energy and power variations; $38 \mathrm{Ah}$ Lithium Iron Phosphate batteries are used in a battery pack composed of 60 series and 40 parallels. Regarding the supercapacitor, its use is not recommended for supplying high energy variations which often occurs in regional train demands.

Table 1. Fuel cell-based hybrid train simulation parameters.

\begin{tabular}{|c|c|c|}
\hline Parameter & PEM-FC & Unit of Measurement \\
\hline Rated power & 180 & {$[\mathrm{~kW}]$} \\
\hline Fuel (Hydrogen) & $>99.98 \%$ & {$[\%]$} \\
\hline Maximum current & $500 \mathrm{ADC}$ & {$[\mathrm{ADC}]$} \\
\hline Maximum voltage & $720 \mathrm{VDC}$ & {$[\mathrm{VDC}]$} \\
\hline Nominal efficiency & 55 & {$[\%]$} \\
\hline
\end{tabular}

The hydrogen infrastructure has been simulated by assuming the input parameters listed in Table 2. The nominal parameters considered as target values to achieve are the nominal temperature, with value of $353 \mathrm{~K}$, and the operating pressure, up to 20 bar. The simulation is run for a full day, 24 hours, and the electrochemical system is considered to have a membrane active area of $100 \mathrm{~cm}^{2}$ and anodic and cathodic chambers with a volume of $0.001 \mathrm{~m}^{3}$.

Table 2. Hydrogen station simulation parameters.

\begin{tabular}{|c|c|c|}
\hline Parameter & PEM-E & Unit of Measurement \\
\hline Membrane Cross Section Area & 100.00 & {$\left[\mathrm{~cm}^{2}\right]$} \\
\hline Nominal Temperature & 353 & {$[\mathrm{~K}]$} \\
\hline Nominal Pressure & 20 & {$[\mathrm{bar}]$} \\
\hline Anode and Cathode Volume & 0.001 & {$\left[\mathrm{~m}^{3}\right]$} \\
\hline Simulation Time & 24 & {$[\mathrm{~h}]$} \\
\hline
\end{tabular}

\section{Simulation Results}

In accordance with the case study described in the previous section, simulations have been performed. The Fuel cell power trend is illustrated in Fig. 5, with $240 \mathrm{~kW}$ average value. The FC power variations are in a limited interval, between $200 \mathrm{~kW}$ and $310 \mathrm{~kW}$, since the fuel cell system provides the energy demands while the battery supply energy and power variations. According to this power trend, the average FC efficiency is approximately $49.5 \%$ and $80 \mathrm{~kg}$ of hydrogen are consumed for a round trip. The battery pack follows the vehicle power trend, achieving $1.5 \mathrm{MW}$ in acceleration and $600 \mathrm{~kW}$ in deceleration. Its state of charge remains within a safe interval, between $40 \%$ and $85 \%$. 


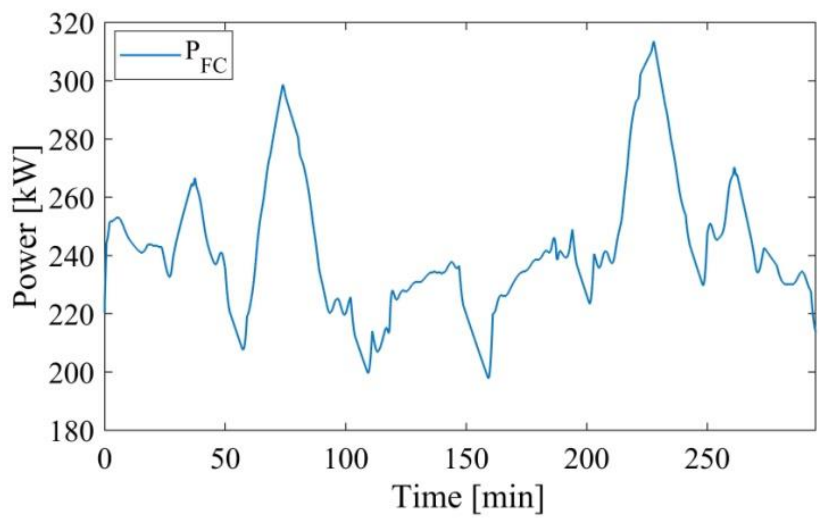

Fig. 5. Fuel cell power trend.

The daily hydrogen demand for the hydrogen train resulted to be $160 \mathrm{~kg}$ for its full operation. The hydrogen facility has been sized and designed considering this daily capacity. The operating current resulted to be $135 \mathrm{~A}$, with 1400 electrolytic cells, assuring a stack voltage efficiency of $54 \%$ and a Faraday efficiency of $94.5 \%$.

Simulations have shown a PEM electrolyzer electric size of $376 \mathrm{~kW}$ and its ancillary system with a power of $8.5 \mathrm{~kW}$. The specific energy consumptions, shown in Fig. 6, resulted to be $56.3 \mathrm{kWh} / \mathrm{kg}$ for the only stack operation, and $1.26 \mathrm{kWh} / \mathrm{kg}$ for the auxiliary energy consumption. The compressor accounts $1.97 \mathrm{kWh} / \mathrm{kg}$ of processed hydrogen, and the dispensing rate for $0.28 \mathrm{kWh} / \mathrm{kg}$.

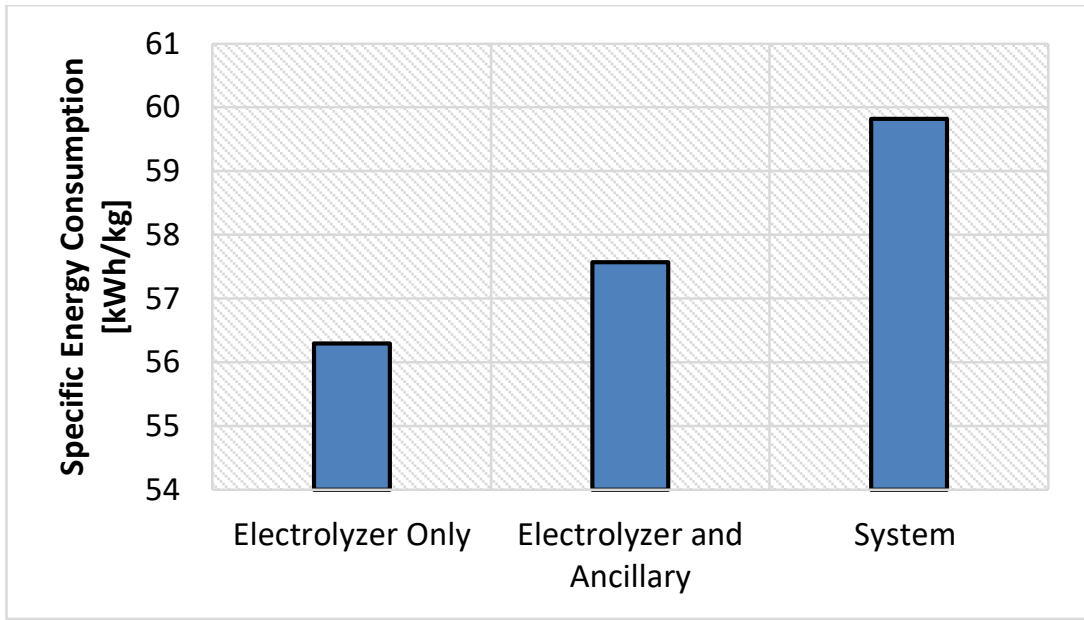

Fig. 6. Specific power consumption.

The overall daily energy demand for the facility resulted to be $9.6 \mathrm{MWh} / \mathrm{day}$, with the highest share belonging to the electrolyzer, as shown in Fig. 7, followed by the compressor and dispensing rate (3.8\%), and by the ancillary system, with a value of $2.1 \%$. The system efficiencies have been found to be $59.2 \%$ if only the electrolyzer is operating, dropping to $55.7 \%$ when the compressor and dispenser are working. The efficiencies are based on the LHV (Lower Heating Value) of hydrogen, considered to be $33.3 \mathrm{kWh} / \mathrm{kg}$. 


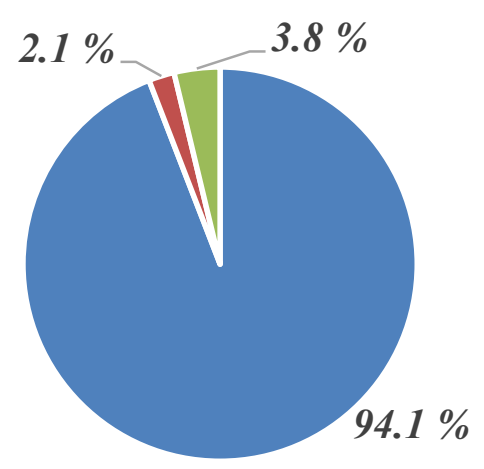

- Electrolyzer Required Energy

- Electrolyzer Ancillary Energy

- Compressor and Dispensing Electric Rate

Fig. 7. Components energy share.

\section{Conclusions}

In this paper, the innovative integration of fuel cell-based vehicles and hydrogen infrastructures is tested. A hybrid regional train, whose powertrain is composed of fuel cell and battery, is simulated on a $360-\mathrm{km}$ route. According to the FC power demand, the hydrogen consumption is $80 \mathrm{~kg}$, with a FC efficiency of $49.5 \%$, for a round trip and two journeys are considered for daily operations. As a consequence, a hydrogen facility, based on PEM technologies, is designed for this line. The infrastructure energy demand is $9.6 \mathrm{MWh}$ /day and more than $94 \%$ is consumed by the electrolyzer, while the remaining part is split between electrolyzer ancillary, compressor and dispensing systems, by showing an overall energy efficiency of $55.7 \%$, based on LHV.

The significant simulation results confirm that the advanced integration of hydrogenbased trains and facilities could represent a sustainable and high-performing solution for a new mobility concept. 


\section{References}

1. IEA, IEA (2019) - Tracking Transport (Paris, 2019)

2. A. Chapman, K. Itaoka, K. Hirose, F. T. Davidson, K. Nagasawa, A. C. Lloyd, M. E. Webber, Z. Kurban, S. Managi, T. Tamaki, M. C. Lewis, R. E. Hebner, and Y. Fujii, Int. J. Hydrogen Energy (2019)

3. Z. Navas-Anguita, D. García-Gusano, J. Dufour, and D. Iribarren, Appl. Energy (2020)

4. B. Sørensen and G. Spazzafumo, in Hydrog. Fuel Cells (2018)

5. I. Staffell, D. Scamman, A. Velazquez Abad, P. Balcombe, P. E. Dodds, P. Ekins, N. Shah, and K. R. Ward, Energy Environ. Sci. (2019)

6. M. Longo, M. Brenna, D. Zaninelli, M. Ceraolo, G. Lutzemberger, and D. Poli, in 2019 IEEE Milan PowerTech, PowerTech 2019 (2019)

7. A. Hoffrichter, P. Fisher, J. Tutcher, S. Hillmansen, and C. Roberts, J. Power Sources (2014)

8. W. Zhang, J. Li, L. Xu, and M. Ouyang, Energy Convers. Manag. (2017)

9. A. Mayyas and M. Mann, Int. J. Hydrogen Energy (2019)

10. J. M. DeCicco, Hydrog. Energy Transit. (2004)

11. H. and F. C. P. Sunita Satyapal, Director, FY 2018 PROGRESS REPORT FOR THE DOE HYDROGEN AND FUEL CELLS PROGRAM (2019)

12. M. Reuß, T. Grube, M. Robinius, P. Preuster, P. Wasserscheid, and D. Stolten, Appl. Energy 200, 290 (2017)

13. A. Bauer, T. Mayer, M. Semmel, M. A. Guerrero Morales, and J. Wind, Int. J. Hydrogen Energy (2019)

14. T. Brown, S. Stephens-Romero, and G. Scott Samuelsen, Int. J. Hydrogen Energy 37, 12731 (2012)

15. K. Reddi, A. Elgowainy, N. Rustagi, and E. Gupta, Int. J. Hydrogen Energy 42, 21855 (2017)

16. K. Kolbe, Transp. Policy (2019)

17. O. Schmidt, A. Gambhir, I. Staffell, A. Hawkes, J. Nelson, and S. Few, Int. J. Hydrogen Energy (2017)

18. P. Fragiacomo and F. Piraino, Energy Procedia 126, 1051 (2017)

19. P. Fragiacomo and F. Piraino, Int. J. Hydrogen Energy (2019)

20. P. Fragiacomo and F. Piraino, J. Energy Storage 17, 474 (2018)

21. P. Fragiacomo and M. Genovese, Int. J. Hydrogen Energy 44, 30237 (2019)

22. M. Genovese, D. Blekhman, C. Xie, M. Dray, and P. Fragiacomo, Int. J. Hydrogen Energy 43, 16623 (2018)

23. P. Fragiacomo and M. Genovese, Int. J. Hydrogen Energy 45, 17685 (2020) 